\title{
SOCIEDADE DO CONHECIMENTO
}

\author{
Vagner de Carvalho Bessa \\ Marcelo Batista Nery \\ Daniela Cristina Terci
}

\begin{abstract}
Resumo: Este artigo retrata tanto a discussão internacional a respeito das novas métricas da sociedade da informação como a exploração desse tema nos últimos anos pela Fundação Seade e, deste modo, o resultado dos esforços nos processos de obtenção, compilação e análise de dados sobre o assunto.

Palavras-chave: tecnologia; informação; conhecimento.

Abstract: This article describes the international debate with regard to the new paradigms of the information society, and the exploration of this subject in recent years by Fundação Seade, in order to assess the efforts towards obtaining, compiling and analyzing data on the subject.

Key words: technology; information; knowledge.
\end{abstract}

$\mathrm{O}$ debate sobre os rumos do desenvolvimento econômico é impulsionado pela difusão dos paradigmas produtivos que atingem o modo de produção de bens e serviços. Existe a plena conviç̧ão de que os segmentos que experimentam profundas mudanças, em função dos impactos das novas tecnologias digitais, mostram potencial econômico para criação de empregos qualificados e geração de renda. Impulsionado pela visibilidade da Internet e a expansão das empresas "ponto.com", esse processo ganhou amplitude e demarcou o significado das novas formas de produção, consumo e conhecimento. De fato, o que se convencionou chamar de "nova economia" envolve um conjunto distinto de significados. Currás, Nanclares e López (2001) advertem que o termo "nova economia" deve ser analisado em aspectos diferenciados. Na perspectiva macroeconômica, a noção tem sido tomada como sinônimo de crescimento do emprego e da produtividade, dentro de um contexto de baixas taxas de juros e inflação, internacionalização da economia americana e mudanças no sistema financeiro internacional, tendo como pano de fundo a difusão das novas tecnologias de informação e comunicação e da Internet. Entrementes, há variações nessa abordagem, pois enquanto alguns defendem que o termo reflete uma mudança de ordem estrutural na economia mundial pas- sível de reprodução em outras regiões (Schreyer, 2000), outros assinalam que o fenômeno registra uma fase do ciclo de crescimento restrito à economia americana nos anos 90, desenvolvida pelos investimentos na nova infraestrutura de telecomunicações, mas de difícil reprodução em outros países.

Do ponto de vista microeconômico, por sua vez, há um entendimento generalizado e mais consensual acerca da liderança que os setores ligados às novas tecnologias exerceram sobre a Globalização Industrial. As fusões e alianças estratégicas entre grandes grupos proporcionaram a emergência de mercados e modelos de negócios nas fronteiras das novas áreas de exploração econômica. A importância das redes de aprendizado se fortalecem como novos padrões de competitividade e as informações dirigidas às inovações tecnológicas e produção de conhecimento passam a constituir um importante insumo para o processo de reestruturação produtiva. Ampliam-se as possibilidades para a aplicação das Tecnologias de Informação e Comunicação - TICs em vários campos e a nova infra-estrutura de telecomunicações proporciona, simultaneamente, a criação de novos produtos e a revitalização de mercados tradicionais em bases tecnológicas renovadas, como nas áreas de telemedicina, de educação a distância e de ação do Estado - por intermédio do governo eletrônico (Cohen et al., 2000). 
$\mathrm{Na}$ ótica social, o ritmo de difusão da nova infra-estrutura de telecomunicações mostra potencialidades inéditas para a abertura e ampliação dos canais de participação nas sociedades democráticas e para o aparecimento dos novos direitos no que se convencionou chamar de "sociedade do conhecimento". O impacto é observado no mercado de trabalho, nas relações comerciais, no crescimento econômico, na forma de produzir, coordenar e distribuir bens e serviços e no cotidiano dos indivíduos; na maneira que adquire informações, aprende, negocia, interage, etc. $\mathrm{O}$ vasto campo de aplicações das novas tecnologias tem conduzido ao debate de como medir os impactos do desenvolvimento e difusão das TICs sobre a vida econômica e social. As instituições reclamam novas regulamentações e incentivos, oferecem e demandam novos saberes.

Entretanto, leituras menos otimistas enfatizam que a difusão diferenciada das novas tecnologias, quando não reforça, repete os padrões de exclusão social presentes em sociedades com profundas diferenciações distributivas. Nesse contexto, a questão da "exclusão digital" ou da "infoinclusão" surge como temática privilegiada que enfatiza a necessidade de políticas públicas voltadas não apenas para universalização ao acesso às novas tecnologias de comunicação e informação, mas também aos benefícios globais da sociedade do conhecimento.

O debate sobre a importância das TICs tem levado a uma ampla discussão a respeito das alterações nas convenções estatísticas necessárias para medir a relevância dos novos processos desenvolvidos no âmbito do que se convencionou chamar de "Sociedade da Informação" ou "Sociedade do Conhecimento". Porcaro (2001) chama a atenção para o fato de os esquemas conceituais, dos sistemas estatísticos oficiais, assentarem-se sobre premissas teóricas umbilicalmente ligadas a uma dada concepção em relação à realidade econômica e social. Segundo a autora, os modelos estatísticos se apropriaram de constructos analíticos ligados à divisão do trabalho da sociedade industrial e ganharam consistência ao desenhar uma representação estatística homogênea e comparativa de uma sociedade cujos padrões culturais, científicos e tecnológicos eram relativamente estáveis, assentados sobre a organização regulada, fordista e circunscrita aos marcos dos Estados Nacionais do pós-guerra.

Os desafios para os sistemas nacionais de estatística são enormes porque compreendem uma agenda aberta. $\mathrm{O}$ extenso campo de aplicações das novas tecnologias de informação e comunicação, a grande heterogeneidade de fontes produtoras de informações, a ambigüidade dos fenômenos, a constante destruição e recriação de barreiras entre os setores de atividades, as dificuldades de mensurar serviços de natureza intangível e as dificuldades de regionalização de uma "economia em rede", impõem desafios ainda maiores. Entretanto, a despeito dessa problemática, há na perspectiva dos organismos internacionais e dos fóruns especializados uma certeza generalizada agindo no intuito de que sejam estabelecidas convenções padronizadas para o exercício de uma métrica dentro das práticas estatísticas adequadas às novas exigências.

\section{ESTATÍSTICAS NA SOCIEDADE DA INFORMAÇÃO}

\section{Indicadores de Compatibilidade Internacional}

Proveniente da necessidade que cada país possui em entender e adaptar as tecnologias globais para as exigências locais, alguns indicadores têm sido compostos para avaliar o nível de progresso tecnológico e a capacidade destes países em participar dessa nova era. A composição de tais índices auxilia as políticas de difusão em mensurar a inserção de cada país em relação aos demais e, em especial, verificar quais são os pontos que proporcionam seu distanciamento daqueles que estão no topo tecnológico. Muitos elementos contribuem para avaliar as realizações tecnológicas, mas em geral poucos são levados em consideração para mensuração, devido à dificuldade de obtenção e compatibilidade encontrada.

Em estatísticas e indicadores existentes de tecnologia, esforços são feitos, sobretudo pela Unesco, OECD e Eurostat (Unesco, 2002), para promover uma maneira sistemática de mensuração, coleta e disseminação desses números, que até o momento estão disponíveis, em sua maioria, apenas para os países industrializados, no que se refere aos recursos humanos e financeiros em P\&D, inovações, citações, patentes, produtos de alta tecnologia, etc. Estatísticas que vêm sendo coletadas tendo por referência os conceitos e as metodologias internacionais estabelecidas em documentos como o Manual Frascati (OECD, 1993), de Oslo (OECD, 1996) e Canberra (OECD, 1995), por exemplo.

Assim sendo, macroindicadores foram desenvolvidos com intento de compreender o processo de produção e aplicação do conhecimento como uma série de sucessivos e necessários estágios que partem da pesquisa básica até a inovação, passando pela pesquisa aplicada e pelo desenvolvimento experimental, transformando-se freqüentemente em um modelo para os países, principalmente para os desenvolvidos, que procuram adaptá-los de acordo com 
suas políticas, porém que encobre as características específicas dos processos de pesquisa científica e de desenvolvimento tecnológico. Essa é uma das principais razões desse modelo ser intensamente questionado pelas escolas e instituições afins, e em conseqüência disso temos a busca incessante por novos indicadores, como os de inovação.

Apesar dos vários modelos criados para mensurar TI, muitas dificuldades são encontradas para quantificar tais questões pelo seu caráter intangível, entretanto existe um número de indicadores que refletem objetivamente o grau de difusão das novas tecnologias e vêm sendo investigados de forma regular por organismos internacionais, como será abordado mais adiante.

Entretanto, existem algumas propostas apontando para que os países em desenvolvimento se estendam além dos indicadores tradicionais de entrada (como centros de pesquisa, pesquisadores, treinamento de pessoal com nível científico e técnico, recursos financeiros) e produtos (artigos publicados, licenças, patentes, número de citações, etc.), incluindo uma mensuração sistemática da capacidade científica e tecnológica (Unesco, 2002). A questão que se sobrepõe, então, é qual a melhor maneira de desenvolver uma estratégia viável para mensurá-los em acordo com as prioridades políticas.

Outra interpretação dada é a realizada pelo Relatório do Desenvolvimento Humano (PNUD, 2002), que faz uma estimativa com relação à justiça econômica do ponto de vista do uso da Internet, concluindo que no âmbito do processo global há a expectativa de que o número de usuários de Internet aumente de 500 milhões para cerca de 1 bilhão até 2005 . Todavia, também é constatado que $72 \%$ dos atuais utilizadores vivem em países da OCDE, tendo elevados rendimentos e contemplando apenas $14 \%$ da população mundial.

Assim como no Relatório de Desenvolvimento Humano, o Technology Achievement Index - $\mathrm{TAI}^{1}$ tem como propósito servir de ponto de partida para uma avaliação tecnológica geral, primeiramente, para que depois sejam examinados outros indicadores de forma mais detalhada (Sagasti et al., 2001:7), para 72 países. Os índices estabelecidos pelo TAI têm como alvo mensurar a tecnologia de cada país, baseados em quatro dimensões: criação de novas tecnologias; difusão e adoção de novas tecnologias; difusão das já existentes, que ainda são básicas para a entrada de novas; e a construção da habilidade humana para a criação e conseqüente adoção de tecnologia.

A metodologia usada para o cálculo é similar à usada para o índice de desenvolvimento humano, entretanto não é designada para medir mudanças no decorrer do tempo. Os dados para sua construção advêm das séries internacionais mais utilizadas e difundidas em relação ao uso de tecnologia, porém alguns países acabam por ser subdimensionados pela falta de informação ou pela qualidade da coleta.

O objetivo dessa proposição não é medir apenas qual país lidera o desenvolvimento tecnológico, mas sim a condição do país como participativo na criação e uso de tecnologia. Para exemplificar, podem-se analisar os componentes do índice, tendo como início a criação de tecnologia. O TAI usa dois indicadores para capturar o nível de inovação na sociedade: número de patentes concedidas per capita, para refletir a intensidade de atividades novas; e o número de royalties e licenças obtidas no exterior, demonstrando a evolução das inovações bem sucedidas ainda utilizadas e com valor de mercado.

Por fim, temos o indicador de habilidade humana que utiliza o número de anos na escola para população acima de 15 anos, que fornece uma boa medida das habilidades proporcionadas pelo ensino básico geral da população, não esquecendo que a qualidade da educação é variável para cada país. Além disso, o número de graduados em ciência, matemática e engenharia, possibilita igualmente uma avaliação dos esforços atuais em desenvolver e avançar o conhecimento em ciência e matemática.

Alguns outros modelos foram produzidos para mensurar a difusão das novas tecnologias de informação, um deles, que merece destaque, é o modelo Inexsk (Mansell e Wehn, 1998) que procura identificar indicadores para o acompanhamento do crescimento de uma sociedade da informação nos países em desenvolvimento. Esse modelo foi desenvolvido para analisar comparativamente a difusão de TI em diferentes países, a partir das seguintes variáveis: infra-estrutura, experiência, habilidades e conhecimento.

Segundo Mansell e Wehn, o grande desafio para a política de difusão é equilibrar os investimentos em equipamentos com o desenvolvimento do capital humano. Os exemplos de Taiwan e Coréia demonstram que é possível se tornar um líder em exportações de bens de TI sem que o padrão de utilização doméstica seja muito afetado. Por esse motivo, a análise dos impactos da TI sobre o crescimento econômico deve abranger uma diversidade de índices, tais como: índice de computadores pessoais; de linhas telefônicas; de produção de eletrônicos; de consumo de eletrônicos; de disponibilidade de recursos humanos qualificados; de alfabetização; de hosts de Internet; e de difusão de televisores; etc. 


\section{Exclusão Digital e Infoinclusão}

O debate sobre a difusão das novas tecnologias tem intensificado o debate relativo aos benefícios ou o acirramento das desigualdades sociais. Ao contrário de um otimismo generalizado sobre as ondas de crescimento provocadas pela nova economia, a apropriação desigual destas tecnologias tem se traduzido em um forte debate a respeito da assimetria entre aqueles que possuem e os que não possuem informação; em que pesem as mudanças tecnológicas e o profundo rompimento com o marco regulatório anteriormente existente, não há ainda um plano de políticas públicas cuja engenharia possibilite alcançar o nível de universalização promovido pelo Estado do Bem-Estar Social no caso da telefonia fixa. O significado de "serviço universal" sofre mudanças e deixa de ser apresentado unicamente como acesso à infra-estrutura de comunicações, passando a ser entendido como a disponibilização de recursos para a criação e disponibilidade de conteúdos informacionais aos quais todos os indivíduos devem ter acesso segundo suas necessidades (Tápia; Rallet, 2000). Duas questões se colocam: como medir a difusão de acessos e, de outra forma, como os indivíduos estão capacitados para lidar com as novas tecnologias. ${ }^{2}$

Do ponto de vista das tecnologias e do pioneirismo, as pesquisas nos Estados Unidos realizadas pela Agência Nacional de Administração de Telecomunicações e Informação do Departamento de Comércio vêm se constituindo como um marco para o monitoramento da questão de exclusão digital entre as pesquisas domiciliares. Do primeiro relatório publicado em 1995, "Falling through the net: a survey of the net: new data on the digital divide" até o quarto relatório "Falling through the net: toward digital inclusion", em 2000, a pesquisa vem assimilando elementos importantes referentes à metodologia de inferência da exclusão e às mudanças no âmbito das novas tecnologias: se, no primeiro estudo, a idéia de inclusão se definia em função da disponibilidade de acesso residencial de telefonia, computadores e Internet, já em 2000 a pesquisa ganha uma novo âmbito: em primeiro lugar, existe um suplemento para cada indivíduo do domicílio e são investigadas a disponibilidade de Internet de alta velocidade e o uso da rede por indivíduos com deficiências físicas e mentais (Navarro, 2001).

Outras pesquisas realizadas no âmbito da OECD mostram que as causas que impedem o acesso dos indivíduos às novas tecnologias podem variar, indo de fatores relacionados à infra-estrutura de telecomunicações ou às dificuldades de acesso em localidades geograficamente isoladas, até motivações de ordem socioculturais. Segundo Navarro (2001), as inovações metodológicas das pesquisas estão registradas na coleta de indicadores para a construção de tipologias familiares e de grupo, pois entende que as questões sobre a exclusão digital não se resumem às características dos indivíduos, mas às necessidades específicas de classes e grupos sociais.

No Canadá, onde as pesquisas são estruturadas pela orientação pragmática das políticas de governo, ${ }^{3}$ a exclusão é pensada como uma segmentação que atravessa todos os grupos socioeconômicos. Em adição à tradicional divisão entre usuários e não-usuários (first divide), há uma segunda segmentação dos não-usuários, que podem ser divididos por sua vez em dois grupos: aqueles que possuem interesses em estar conectados, no entanto não estão, em função de barreiras de custo, habilidades e capacidade de uso; e aqueles que possuem pouco ou nenhum interesse nos serviços oferecidos (second divide), que resulta de uma diferença em relação à percepção de valores, dificuldades com a língua, de usabilidade ou de um desestímulo em relação à pouca densidade de conteúdos sociais e geração de oportunidades, como informações sobre emprego, moradia ou capacitação (Navarro, 2001: 32).

As primeiras referências para a medição desse processo de exclusão digital nas estatísticas produzidas na Fundação Seade se remetem a Pesquisa de Condições de Vida 1998. ${ }^{4}$ A pesquisa, que já trazia desde suas primeiras versões (1990 e 1994) dados a respeito do número de linhas telefônicas residenciais, incorporou questões relativas à existência de telefones celulares e computadores nos domicílios. Esse levantamento possibilitou a formulação de indicadores sobre a disponibilidade de terminais de acesso telefônico e computadores a partir de cruzamentos com as informações de renda do chefe da família, gênero e demais condições dos domicílios e de seus ocupantes, permitindo traçar um retrato das condições de acessibilidade dos indivíduos às tecnologias básicas para o acesso às redes digitais. Segundo os dados da pesquisa, para cada mil famílias com renda superior a 20 salários mínimos, havia cerca de mil computadores por domicílio (média de um para cada domicílio), enquanto para aqueles com até dois salários, a densidade era de 160 terminais para cada grupo de mil famílias. ${ }^{5}$ Tal disparidade pode ser vista também por meio da apropriação das novas tecnologias segundo o grau de escolaridade dos residentes: observando a distribuição dos indivíduos com 7 anos ou mais que freqüentam algum nível de ensino regular, $24 \%$ dos estudantes dispunham de PCs em suas residências na Região 
Metropolitana de São Paulo; entretanto, enquanto entre os estudantes de escolas públicas esse percentual era de $11 \%$, para aqueles que estudavam em escolas particulares, esse número alcançava $62 \%$ - ou, de outra forma, $66 \%$ dos alunos que dispunham de computador em seus domicílios estavam no sistema privado (Bessa; Tápia, 2003).

Entretanto, se o acesso residencial contempla uma análise importante sobre a disponibilidade de computadores e telefones fixos e celulares, questões que dizem respeito a essas tecnologias fora dos domicílios, assim como as motivações, freqüência, intensidade e barreiras para o seu uso, somente poderiam ser contempladas em uma pesquisa específica do tema.

A pesquisa "Hábitos de leitura e uso da Internet", resultado do convênio entre a Fundação Seade e a Imprensa Oficial do Estado - Imesp, foi capaz de avançar significativamente nesse campo, com uma investigação específica sobre o uso da Internet em suas múltiplas dimensões. ${ }^{6}$ A pesquisa permitia avaliar, entre outras questões, o uso da rede mundial de computadores fora das residências e explorar as barreiras que impediam os indivíduos de acessar as redes digitais, segundo várias segmentações (renda, gênero, faixa etária, cor e escolaridade).

Segundo os dados da pesquisa, a proporção de indivíduos que acessam a Internet é de 18,9\% na RMSP, sendo a proporção de domicílios com internautas de apenas 8,5\% dentre aqueles com renda per capita de até meio salário mínimo. A maior parte acessa a web nos domicílios

\section{GRÁFICO 1}

Distribuição da População em Idade Ativa que usa Microcomputador, mas não utiliza Internet, segundo Motivo Principal para Não-Utilização da Internet Região Metropolitana de São Paulo - 2001 ${ }^{1}$

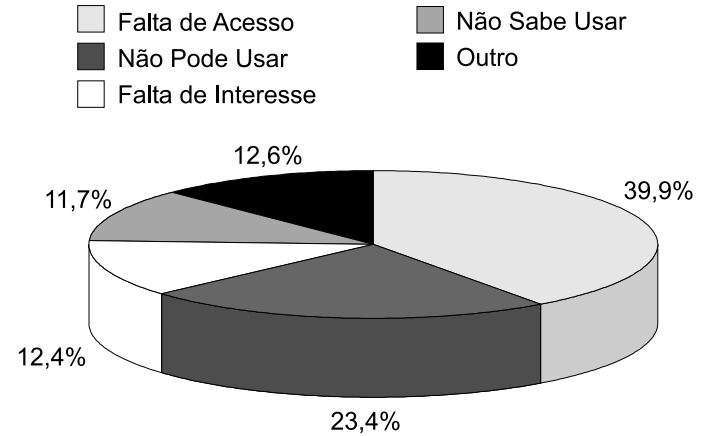

Fonte: SEP. Convênio Seade - Dieese. Suplemento da Pesquisa de Emprego e Desemprego $-P E D$.

(1) Os dados referem-se ao período de abril a agosto de 2001.
$(61,7 \%)$ ou no trabalho (46\%). ${ }^{7} \mathrm{O}$ acesso compartilhado em lugares públicos é utilizado por apenas $16 \%$ dos indivíduos, sendo ainda menor o acesso pela escola e pela universidade $(12,3 \%) .{ }^{8}$ Esses dados indicam o espaço para uma política de infoinclusão, uma vez que o acesso à Internet ainda é extremamente dependente dos recursos despendidos pelos próprios indivíduos e pelas empresas.

Conforme Bessa e Tápia (2003: 88), “a distribuição dos bens e serviços decorrentes das novas tecnologias digitais leva à apropriação desigual dos seus benefícios, e esse processo não decorre do tempo relativamente pequeno entre a chegada da Internet no Brasil e o levantamento das informações da pesquisa, como alguns poderiam sugerir. Mais do que isso, os dados mostram que o entrelaçamento entre a concentração de renda e o nível de escolaridade, por um lado, e o acesso a computadores, de outro, colocam obstáculos de fundo estrutural que podem vir a auto-reforçar os níveis de exclusão já existentes e que estão longe de ser resolvidos pelas políticas tradicionais."

\section{Governo Eletrônico}

A discussão sobre Governo Eletrônico demarca um compromisso recente de proposições na forma do exercício da democracia e da administração pública. Conseqüentemente, não há ainda uma agenda para produção de informações desse âmbito entre instituições estatísticas, sendo os levantamentos limitados à produção de indicadores em relação à expansão dos serviços públicos pela Internet, mais com a finalidade de divulgação do esforço das administrações governamentais em produzir serviços pela WEB do que em instituir um conjunto de indicadores com requisitos estatísticos propriamente ditos.

A Fundação Seade, além de cumprir papel estratégico no governo eletrônico como núcleo de produção de informações para monitoramento das políticas públicas e transparência das ações governamentais, desenvolve atividades para o levantamento de estatísticas voltadas para ações nessa área. As informações estão centradas na coleta de informações diretas obtidas pela Pesquisa Municipal Unificada - PMU e na montagem do "Guia da Oferta de Informações e Sistemas do Governo do Estado de São Paulo".

Na primeira versão da PMU, a coleta destinava-se a observar a difusão dos equipamentos de informática entre as várias instâncias da administração pública municipal. Após algumas tentativas pioneiras para a obtenção 
de dados de forma mais eficiente, em 1999, chegou-se a um levantamento de informações mediado por uma concepção conceitual bem mais definida - passa-se da noção genérica de "informatização" para o conceito integrado de "Governo Eletrônico". Isso se deu em função do próprio amadurecimento da discussão nos núcleos de inteligência das administrações públicas e nos fóruns acadêmicos, voltados para temas estratégicos, como democracia e participação. ${ }^{9}$

Embora não haja ainda consenso para a definição precisa de governo eletrônico (assim como para a definição de comércio eletrônico, como veremos adiante), já se notam algumas linhas de concordância sobre seus aspectos mais importantes. O governo eletrônico não significa apenas o uso da Internet para tornar disponíveis informações e serviços aos cidadãos de forma ininterrupta, onde e no momento que eles os desejam. Governo eletrônico implica o desenvolvimento de uma estratégia para implementar formas mais eficazes, descentralizadas e transparentes de gerenciamento público, além de garantir a todos os benefícios da Sociedade da Informação dentro de uma perspectiva democrática e de coesão social.

Nesse sentido, a estrutura da PMU de Comunicações e Informática é organizada em torno de alguns eixos básicos: disseminação de serviços a distância, infra-estrutura digital, Internet, política de recursos humanos, parcerias e políticas de inclusão digital e comércio eletrônico. Em um plano mais concreto, são investigados a disseminação dos recursos físicos ligados às tecnologias de informação e à infra-estrutura de telecomunicações (parque de computadores, recursos multimídia, existência de redes de comunicação e da Inter e Intranet), as aplicações de recursos telemáticos como instrumento de gestão administrativa e o esforço dos municípios no que se refere a treinamento e capacitação na área de informática.

Além disso, investigam-se as prefeituras que dispõem de páginas na Internet, indicando as informações de utilidade pública e serviços disponíveis na página e os recursos oferecidos para a interação on-line entre a administração municipal e os cidadãos (e-mail, chats, grupos de discussão, etc.), busca-se identificar tanto a existência de diretrizes programáticas de difusão de novas tecnologias, como políticas de universalização de acesso público a redes de comunicação de dados e à Internet, por meio da disseminação de terminais on-line em quiosques, bibliotecas, postos de saúde, escolas, etc. e verifica-se se os esforços das prefeituras na área da política da informação são realizados mediante parcerias com o setor privado e os setores não-governamentais.
Os resultados da primeira PMU apontam para um quadro representativo da estrutura do governo eletrônico entre as prefeituras. Embora a temática relacionada ao Governo Eletrônico tenha importância crucial para a construção de novas relações entre o chamado "poder local" e os cidadãos, no Estado de São Paulo a maioria delas ainda não assimilou importantes elementos que compõem a agenda pública focalizada na Sociedade da Informação. A incorporação das novas tecnologias da informação, que parece se dar em níveis acelerados, não tem revelado os efeitos desejáveis sobre a performance do setor público municipal como, por exemplo, maior transparência na administração ou fortalecimento da "cidadania eletrônica".

O esforço para a assimilação de novas tecnologias é impulsionado pela necessidade de informatização mais imediata de alguns setores da administração municipal, sobretudo pelas demandas da Secretaria de Finanças (dada a necessidade de organizar a arrecadação municipal ${ }^{10}$ ), e também nas áreas sociais, cujas relações com outras instâncias governamentais (convênios, repasses, etc.) exigem a informatização dos dados. Sintoma da pouca importância que as prefeituras conferem ao governo eletrônico é o fato de somente $21 \%$ delas contarem com alguma estrutura administrativa, formalizada e com capacitação específica, voltada para a gestão da TI (núcleos, secretarias, centro de processamento de dados, etc.).

A inserção das prefeituras na web por meio de home pages alcança $19 \%$ das administrações no Estado de São Paulo, em relação a $83 \%$ nos Estados Unidos. Predominam sites pouco estruturados em informações de serviços de utilidade pública ou mecanismos de interatividade para o alargamento da participação popular em espaços virtuais de discussão (fóruns, salas de debates, murais virtuais). Nesse sentido, os serviços on-line limitam-se a um centro de informações com perfil "estático" (apenas relacionando políticas, serviços e procedimentos). São poucos os que se estruturam em função de uma postura "dinâmica" (serviços realizados prontamente por meio do envolvimento de todos os setores da administração pública).

Vale notar que a discussão sobre a difusão das novas tecnologias da informação e a gestão pública ganha espaço no âmbito das ações estratégicas do Estado em diferentes níveis (federal, estadual e municipal) e nas instâncias do poder legislativo e judiciário (Takahashi, 2000). As experiências mais reconhecidas estão ligadas à declaração do imposto de renda pela Internet e ao sistema eleitoral em meio eletrônico, ambas de referência internacio- 
nal. ${ }^{11}$ Entretanto, no âmbito dos governos estaduais, algumas experiências têm ocorrido para racionalizar o processo de compras, com a montagem de pregões eletrônicos e a informatização do sistema de arrecadação e gestão orçamentária, cujos efeitos mais imediatos são: redução dos custos de arrecadação, diminuição do volume de transações realizadas em papel e de erros de preenchimento e agilidade para a identificação de contribuintes devedores ou omissos. ${ }^{12}$

\section{Guia da Oferta de Informações e Sistemas}

Outra pesquisa realizada com objetivo de mapear a infra-estrutura do parque de informática e a disponibilização de serviços públicos é o Guia da Oferta de Informações e Sistemas ${ }^{13}$ que visa dar visibilidade ao acervo de informações do Estado de São Paulo por meio da divulgação dos sistemas informatizados em operação, localizados nas diversas Secretarias e órgãos vinculados. Além de mostrar quais são e onde estão as principais informações produzidas e armazenadas pela administração pública estadual, facilita o acesso às informações e estimula o seu uso, bem como o intercâmbio de experiências entre órgãos, incluindo a troca de sistemas e informações operacionais.

O Guia possui dois módulos: no primeiro, estão reunidas informações a respeito dos sistemas informatizados, fornecendo dados individuais sobre cada sistema desde as principais características dos bancos de dados e sistemas gerenciais existentes no Estado, tais como nome, situação atual, ano de implantação, objetivo, assuntos específicos, natureza, meios de acesso e disponibilização das informações, softwares utilizados e tipos de saídas possíveis, além de dados sobre o responsável pelo sistema. No segundo módulo, são abordados os aspectos relativos aos ambientes de informática, mostrando a situação da área de informática nas instituições públicas estaduais, no que se refere a ambientes, equipamentos, programas e recursos humanos existentes. A constituição dos ambientes é feita de forma detalhada (grande e médio portes, microinformática, internet e intranet); os equipamentos, formas de conexão utilizadas e pessoas alocadas no setor de informática por tipo de atividade e nível de escolaridade também são levantados.

Cabe ressaltar que a base de dados é composta de maneira desagregada, por secretarias e órgãos do governo estadual, contudo permite delinear o perfil da informática no Estado constituindo um instrumento valioso para os estudos futuros.

\section{Comércio Eletrônico}

A Tecnologia da Informação e Comunicação constitui um novo campo que começa a ser explorado por instituições como agências estatísticas e de governo, institutos de pesquisas, consultoria e planejamento e pela área acadêmica. Um bom exemplo dessa condição envolve as contradições originadas em torno do comércio eletrônico, ou e-commerce.

Desde sua incursão, a definição de comércio eletrônico tem sido a fonte de muitos debates. Mediante a exigência de conhecimento ditada pelo cenário socioeconômico internacional, discute-se um arcabouço teórico, de medidas estatísticas e de definições a serem adotadas para melhor compreender a interação entre tecnologia e o processo de negócios. Desse modo, discute-se sobre a identificação de oportunidades, o aperfeiçoamento das aplicações de estudos e políticas, a aquisição de maior entendimento e melhor visão de todos os atores econômicos e seus objetivos e a revisão de pressupostos já estabelecidos.

Além disso, investiga-se a maneira mais acertada de produzir índices que retratem a intensidade e o impacto do comércio eletrônico, possibilitando fundamentar critérios e diretrizes para modelos teóricos, metodológicos e conceituais que permitam o incremento da comunicação e a colaboração entre empresas, o desenvolvimento e aperfeiçoamento de previsões para futuras necessidades no âmbito da sociedade da informação.

Tantas incógnitas confirmam a necessidade de estabelecer um conjunto de conceitos que permitam compreender melhor a nova economia. Entrementes, segundo Porcaro, pode-se verificar que a maioria das definições existentes de e-commerce difere de alguns elementos centrais: abrangência das atividades e/ou os tipos de transações incluídas na definição ampla (comércio, transporte, marketing, propaganda, saúde, educação, engenharia, serviços de informação, concorrência pública, etc.) ou restrita (somente comércio varejista e entrega eletrônica).

O que se tem hoje são descrições, das definições muito abrangentes às muito limitadas, que variam conforme a procedência, ou seja, diferem de acordo com cada pesquisa, com quem a elabora e com o local em que é feita. Com o adendo de serem freqüentemente posicionadas mais por questões políticas e/ou mercadológicas que por propostas práticas de mensuração. 
Isso porque os agentes econômicos têm muito a ganhar com o estabelecimento de seu envolvimento nesse novo seguimento. Conseqüentemente, os principais atores inseridos nessa empresa também estão trazendo sua própria definição, dirigida exclusivamente por imperativos de marketing, visando estratégias planejadas para conseguir vantagens na economia digital.

Um desafio adicional ao esclarecimento do tema é ocasionado pelo contínuo desenvolvimento da microeletrônica, da computação (hardware e software), das telecomunicações, da optoeletrônica e da biotecnologia, ${ }^{14}$ responsável pela alta velocidade das mudanças nas estruturas das transações eletrônicas e na natureza dos processos de negócios, produzindo transformações nas referências usadas para apreender a economia eletrônica.

A respeito da novidade desse âmbito, pode-se citar a decisão da Organisation for Economic Co-operation and Development (OECD), que apenas em abril de 1999 decidiu criar um grupo para compilar definições politicamente relevantes e estatisticamente viáveis a respeito de comércio eletrônico (Colecchia et al., 2000:10). Idealmente,

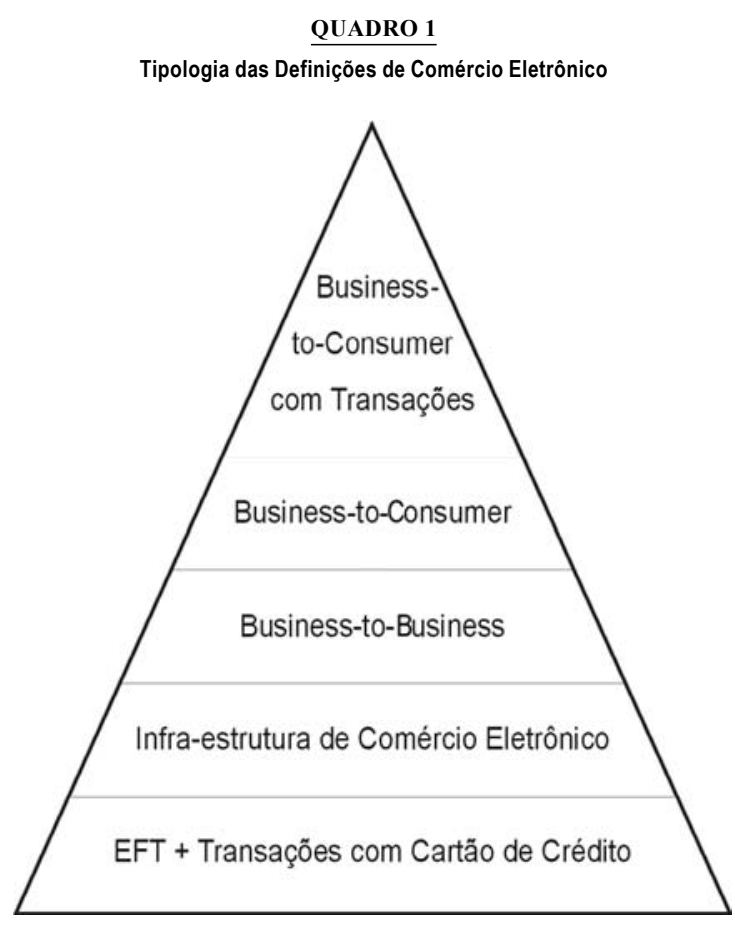

Fonte: OCDE (1997). a intenção desse conjunto de especialistas é desenvolver uma definição realística, facilmente compreensível e mensurável, ampla o bastante para ser mantida com o decorrer do tempo, além de estreita o bastante para constituir uma concepção objetiva.

Uma referência fundamental é a OECD. Estudando suas muitas publicações torna-se evidente o tom ponderado de suas asserções. Contudo, após esclarecer a dificuldade de mensurar o comércio eletrônico (a diversidade dos conceitos, a incompatibilidade de muitas estatísticas oficiais e a heterogeneidade das fontes privadas, etc.), a ela pode ser atribuída a seguinte definição: comércio eletrônico refere-se geralmente a toda forma de transação relacionada com atividades comerciais, incluindo organizações e indivíduos que estão baseados no processo e transmissão de dados digitalizados, incluindo texto, som e imagens (OCDE, 1997).

Concomitantemente, Statistics Canada descreve comércio eletrônico como uma forma de conduzir negócios, uma "transação"15 que compreende a transferência da posse ou da propriedade de uso de recursos tangíveis ou intangíveis e que deve ser mediada necessariamente por meio do uso de computadores. Na mesma linha a Electronic Commerce in Canada apresenta duas definições. A definição "técnica" diz ser o comércio eletrônico uma atividade comercial conduzida por meio de redes que ligam dispositivos eletrônicos (principalmente computadores). Na definição "básica" o comércio eletrônico é tido como uma maneira barata de conectar computadores, a fim realizar as tarefas que tradicionalmente têm absorvido muito tempo e dinheiro dos negócios. Coisas como a venda de produtos, faturas, controle de inventários e comunicação com clientes e fornecedores. ${ }^{16}$ Já o U. S. Bureau of the Census define-o como algum processo que uma organização de negócios conduz mediado por rede de computadores (Mesenbourg, 2001).

O Eletronic Commerce Promotion Council of Japan ao questionar o que é comércio eletrônico, expõe a seguinte resposta: comércio eletrônico suporta uma infinidade de atividades - design de produto, fabricação, anúncio, transações comerciais, estabelecimento de clientes -usando uma variedade de tipos de redes de computador (ECOM, 1996 apud OCDE, 1997). Segundo a European Information Technology Observatory, ${ }^{17}$ comércio eletrônico é o suporte das atividades de negócio que conduzem a troca de valores por meio das redes de telecomunicações (EITO, 1997 apud OCDE, 1997). Para a Comissão Européia, comércio eletrônico está baseado no proces- 
samento e transmissão eletrônica dos dados e abrange diversas atividades, incluindo negociação eletrônica de bens e serviços, entrega on-line dos conteúdos digitais, transferência eletrônica de fundos, negociação eletrônica de ações, transmissão eletrônica de notas promissórias, pesquisas on-line, requerimento público, marketing direto ao consumidor, serviços de pós-venda, etc. (Commission Europeu, 1997 apud OCDE, 1997). A World Trade Organization (WTO), por sua vez, apresenta-o como a produção, anúncio, venda e distribuição de produtos por meio de redes de telecomunicação. ${ }^{18}$

Entretanto, verificaram-se diferentes enunciações até em publicações da mesma instituição, refletindo que, na verdade, nenhuma das definições constituiu um conceito conclusivo, o que torna ainda mais evidente a variedade de significados e amplitudes existentes tanto nos diversos grupos que estudam o assunto como nos vários países.

Uma estratégia que parece cada vez mais consensual, dá-se no plano dos temas relevantes para a abordagem do comércio eletrônico e que seriam objeto de pesquisa direta. Segundo Porcaro (2001), esses temas se dão apenas em torno dos aspectos relativos a mensuração propriamente dita das transações eletrônicas, mas circunscreve um núcleo de questões que incidem sobre as condições de expansão dessas atividades. Nesse sentido, as pesquisas devem comportar questões que revelem os aspectos relativos a barreiras, uso, infra-estrutura e impactos do comércio eletrônico sobre as atividades das empresas.

Barreiras - Com toda a disseminação tecnológica e investimento por parte das empresas para propiciar cada vez mais a comodidade do consumidor e, conseqüentemente, ultrapassar a concorrência, vários setores ou empresas ainda não adotaram o comércio eletrônico como prática. Para perceber quais são os principais empecilhos, tanto no que diz respeito à infra-estrutura, quanto ao uso por parte dos consumidores e/ou fornecedores e a falta de capacitação dos funcionários com as novas tecnologias, perguntou-se às empresas quais elementos poderiam estar envolvidos com esses aspectos impeditivos.

As barreiras que dificultam o progresso do comércio eletrônico podem ser identificadas por aspectos como o ainda restrito acesso e uso da Internet, a baixa instrução e treinamento em informática, a falta de proficiência em língua estrangeira ou o simples desconhecimento do assunto. As ações do setor público (má-coordenação ou regulamentação, por exemplo) e as questões políticas e legais também constituem impedimentos para o bom desenvol- vimento do e-commerce. Até mesmo elementos "culturais" podem representar obstáculo, visto que a comercialização por esse meio depende da existência de um sentimento de segurança do consumidor que precisa depositar confiança na companhia da qual está comprando, ou seja, que poderá efetuar o pagamento e o produto será entregue ou o serviço prestado, protegendo a sua privacidade e impedindo quaisquer tipos de contratempo. Ademais, a própria confiança proporcionada pela estrutura que o suporta é um fator "institucional" que deve ser levado em consideração.

Em todos esses casos, surge a necessidade de captar as informações com um recorte apropriado no qual, em pesquisas domiciliares, é essencial obter os resultados por faixa etária, gênero, nível educacional, ocupação e renda. Concomitantemente, pela perspectiva das pesquisas econômicas, o ano de constituição da empresa, características do(s) proprietário(s), segmentação por porte, receita e setor de atividade, localidade em que está instalada, capacitação exigida e treinamento oferecido pelas empresas são alguns exemplos das variáveis fundamentais a serem estudadas.

Uso - Em um quadro de crescente competitividade do mercado, a eficiência torna-se um fator fundamental para determinar a diferenciação de produtos e serviços, estabelecer nichos de mercado, manter e buscar novos clientes. Desse modo, a tendência em se optar por um tipo de relacionamento comercial via Internet aparece como uma ótima alternativa.

Hoje, o volume do comércio eletrônico é relativamente pequeno. Entretanto, ele está crescendo rapidamente, evolução ligada a elementos como o aumento da confiabilidade do sistema, a redução do tempo de transação e de custos operacionais, expressos em tudo aquilo que envolve o seu uso - a intensidade, o volume, o valor, a qualidade, a eficiência e a natureza ${ }^{19}$ das transações.

Em vista disso, em alguns países como os Estados Unidos investigam-se, por exemplo, o custo comparativo da aquisição e o tempo para a entrega do produto ou a satisfação do cliente e a qualidade do relacionamento com o fornecedor, com o objetivo de calcular a capacidade para a realização do comércio eletrônico.

Infra-estrutura - Todos os aspectos estão fortemente interligados, o comércio eletrônico exige tecnologias e serviços de telecomunicações eficientes e amplamente disponíveis e isso envolve a utilização de computadores, roteadores e outros hardwares envolvidos na interconexão, 
satélites e comunicação de redes de fibra ótica e sem fio, sistemas, aplicativos, etc.

Da mesma forma, forte impressão do impacto ocorre quando observamos o mercado de trabalho, já que para suportar processos de negócios eletrônicos e conduzir transações on-line são necessários serviços de suporte, tais como desenvolvimento e hospedagem de sites, consultorias, pagamentos eletrônicos e capital humano, como programadores, analistas, projetistas e especialistas, utilizados nos negócios e comércios eletrônicos. Busca-se, assim, a adequação dos currículos levando em conta as maneiras de proporcionar aos profissionais capacitação suficiente para o desempenho oportuno das funções definidas por essas novas formas de atividade, em um esforço de desenvolver as capacidades humanas, com ênfase na educação e emprego, nos setores mais diretamente afetados pelas TICs.

Impactos - Por fim, deve-se ressaltar que as medidas estatísticas sobre os impactos do e-commerce vêm recebendo, ainda, pouca atenção (Porcaro, 2001). Contudo, importantes exemplos de levantamentos puderam ser citados e mais poderiam ser mencionados. Desse modo, por intermédio de tais pesquisas, a avaliação das variáveis pesquisadas ajudará a responder algumas questões: o número de computadores das empresas pode indicar o grau de informatização em um setor de atividade econômica. Indicadores de conectividade oferecem uma visão do nível de conexão das empresas com o mundo digital. Uma análise dos motivos que levam a empresa a não utilizar o comércio eletrônico permite inferir onde os investimentos devem ser feitos. E assim por diante, envolvendo um conjunto de informações que permitem entender melhor as mudanças e diferenças nas dinâmicas, nos padrões e na difusão das novas tecnologias.

Esses aspectos são importantes para se entender como foi feito o levantamento de informações sobre o tema pela Pesquisa da Atividade Econômica Paulista - Paep. No caso da primeira versão da pesquisa, em 1996, considerava-se que o levantamento de informações sobre tecnologias de informação e comunicação entre as empresas era um elemento fundamental para a descrição do processo de reestruturação produtiva, dado que esse processo vem alterando as formas de produção e distribuição das corporações empresariais.

A emergência de "novos modelos de negócios" surge na esteira da ampliação das redes corporativas e do rápido desenvolvimento das redes corporativas de transmis- são de dados, que possibilitam a hierarquização das redes de valor em torno de novos modelos organizacionais. Nesse sentido, as informações sobre TICs se limitaram à captação de dados relativos ao parque de computadores e às redes de transmissão de dados. O levantamento permitiu inferir o nível de difusão das redes digitais locais (LAN) e redes de longas distâncias - WAN entre as empresas. A existência de redes para transações econômicas com fornecedores, clientes e outros agentes foram abordados com a finalidade de se observar a formação de elos comerciais e produtivos na cadeia de suprimentos no que se convencionou chamar de supply chain management, conceito que então organizava a abordagem da pesquisa no capítulo de tecnologias de informação.

A segunda versão da pesquisa apresentava modificações importantes, construídas por algumas diretrizes. No capítulo de tecnologia da informação o conceito de infraestrutura é ampliado com informações sobre a velocidade de conexão de rede e aprofundam-se as questões relativas ao uso da Internet. Em que pese a ausência de um consenso sobre a melhor metodologia para a apuração do que se convencionou chamar de "comércio eletrônico", esse tema ganha destaque e amplia sua importância na pesquisa, com um capítulo exclusivo dedicado ao tema.

Foram apropriadas questões das pesquisas realizadas em vários países, destacando-se as do Canadá e dos Estados Unidos. Em termos gerais, foi construído um núcleo de questões que segue de perto as recomendações observadas internacionalmente: levantar informações a respeito de barreiras, infra-estrutura e impactos, seguindo muito de perto a proposta canadense. Entretanto, como a definição de comércio eletrônico do Canadá mostrou-se por demais restrita, resumindo-se basicamente a Internet, a opção da Paep foi mais flexível, oferecendo uma definição suficientemente genérica, como sugere a experiência americana. A fim de superar o conflito entre definições fechadas ou genéricas de comércio eletrônico, foram investigados separadamente os canais mais comuns de vendas por meio eletrônico, sejam tradicionais (cartões de crédito on-line, cheque eletrônico, etc.), sejam aqueles mais modernos (Internet, EDI, web-EDI), a fim de possibilitar que os pesquisadores e usuários pudessem compatibilizar as informações extraídas da Paep com suas opções metodológicas particulares.

Outro elemento fundamental apropriado pelas pesquisas econômicas é o peso dos setores de tecnologia que tornam a economia digital possível. Isso coloca modelos de análise para a Economia da Internet, na qual o Setor 
Informacional tem um recorte horizontal na perspectiva da convergência dos setores de segmentos específicos do comércio e serviços de telecomunicações, informática e audiovisual. Entretanto, além desses serviços, são de fundamental importância os domínios da indústria eletroeletrônica e informática, fornecedores de equipamentos e softwares de rede e banco de dados, os quais determinaram as condições de oferta de infra-estrutura das novas infovias digitais. Entretanto, há ainda no plano internacional uma intensa discussão sobre os contornos mais precisos desse novo arranjo de atividades (Zabelsky, 1997; Colecchia, 2001).

Esse grupo de segmentos apresenta forte concentração de investimentos e rápido crescimento ao longo dos anos 90, impulsionando o ciclo de acumulação da economia dos países desenvolvidos (Departamento de Comércio, 1999), compreendendo desde a produção de computadores e softwares até os serviços de comunicação de voz, imagem e dados.

\section{CONCLUSÃO}

Nos últimos 20 anos as políticas para ciência e tecnologia desenvolveram-se substancialmente, uma vez que a competitividade econômica clamava por uma redefinição do papel do conhecimento na construção das vantagens competitivas das empresas e na forma de organização do Estado. Concomitantemente, a adoção de programas ligados à Sociedade da Informação, no contexto dos países desenvolvidos e em desenvolvimento, reforçou a discussão sobre a necessidade de indicadores e análises técnicas, econômicas e sociais no âmbito das agências estatísticas. Todavia, seja porque as estruturas tecnológicas e patrimoniais encontram-se em pleno processo de transformação, seja porque os processos relacionados à sociedade da informação não podem ser descritos unicamente em termos tecnológicos strictu sensu - dado que incorporam simultaneamente determinações qualitativas de ordem sociocultural, ligadas à dimensão da experiência e ao conhecimento -, as dificuldades desse processo não são nada desprezíveis.

Entrementes, questiona-se a identificação de oportunidades, o aperfeiçoamento das aplicações de estudos e políticas, a aquisição de maior entendimento e melhor visão de todos os atores econômicos e seus objetivos, e a revisão de pressupostos já estabelecidos, pois o que se tem hoje, das definições muito abrangentes às muito limitadas, são descrições que variam mediante a procedência, ou seja, que diferem de acordo com cada pesquisa, com quem a elabora e com o local em que é feita. Além disso, uma vez que os pressupostos dessa discussão estão amparados em algumas transformações importantes que se dão no âmbito da sociedade e da economia, mas que não há um consenso sobre as formas de conceituar esse processo, há uma forte ambivalência a respeito dos melhores indicadores para aferir o desenvolvimento social e econômico dele resultante.

Existe uma tensão entre indicadores de compatibilidade internacional e a formulação de estatísticas vinculadas às questões políticas específicas de cada país, questões derivadas da forma como são organizados os programas políticos, que por sua vez estão correlacionados a contextos históricos, governamentais e demográficos particulares, que insinuam uma importância diferenciada para grupos imigrantes, perfil escolar da população, nível de renda, etc. Além disso, como foi observado neste artigo, é possível apontar pontos comuns dentre os indicadores genéricos coletados sistematicamente por países de todo o mundo. No entanto, também se verificou que um certo consenso dirigido àquilo que se deveria medir não leva à homogeneidade metodológica. Da Ásia à Europa, da África à América, os governos estão discutindo e realizando alterações nas convenções estatísticas necessárias para medir os muitos aspectos ligados à "Sociedade do Conhecimento". Com relação à condição nacional, verificam-se significativos progressos com o desenvolvimento de portais e sites, a difusão de terminais de acesso público e a propagação de prêmios de excelência, fóruns de discussões e projetos de inclusão digital. ${ }^{20}$ Destarte, é possível afirmar que no Brasil, como em todo o resto do mundo, as pesquisas sobre Tecnologia da Informação ainda estão em formação.

São inúmeras as tarefas que se impõem às instituições públicas na construção dos fundamentos da sociedade do conhecimento. O processo de difusão e adoção de novas tecnologias exige um conjunto de conhecimentos e serviços eficientes e amplamente disponíveis. Fatores que envolvem a montagem de uma infra-estrutura regulatória adequada, o suporte à organização de um sistema de ciência e inovação tecnológica e investimentos direcionados para a educação de qualidade, apenas para destacar alguns. Do mesmo modo, forte impressão do seu impacto ocorre, por exemplo, quando observamos o mercado de trabalho: para suportar processos de negócios eletrônicos e conduzir transações on-line são necessários serviços de suporte, tais como desenvolvimento e hospedagem de sites, 
consultorias, pagamentos eletrônicos e capital humano, como programadores, analistas, projetistas e especialistas, utilizados nos negócios e comércios eletrônicos. Por conseguinte, busca-se a adequação dos currículos levando em conta formas de proporcionar aos profissionais capacitação suficiente para o desempenho oportuno das funções definidas por novas formas de ocupação.

Nesse contexto, fica evidente a necessidade de medir a composição física e a direção que as TICs podem estar tomando. Portanto, cabe lembrar que importantes exemplos de levantamentos podem ser citados, visto que, além das pesquisas realizadas pela Fundação Seade, o IBGE (Instituto Brasileiro de Geografia e Estatística) coleta dados como número de PCs e de acesso doméstico à Internet, a Fapesp (Fundação de Amparo à Pesquisa do Estado de São Paulo) afere o número de domínios, ${ }^{21}$ o Ministério da Educação avalia o acesso à TI na escola e a disponibilidade de serviços de suporte, o Ministério do Planejamento levanta a abrangência dos serviços públicos via Internet, institutos independentes estimam informações como acesso à Internet no trabalho e usuários de telefonia celular, etc. Assim, de posse dos resultados, a avaliação das variáveis pesquisadas ajudará a responder a algumas questões: o número de computadores das empresas pode indicar o grau de informatização em um setor de atividade econômica; indicadores de conectividade oferecem uma visão do nível de conexão das empresas com o mundo digital; uma análise dos motivos que levam a empresa a não utilizar o comércio eletrônico permite inferir onde os investimentos devem ser feitos; e assim por diante, envolvendo um conjunto de informações que permitem entender melhor as mudanças e diferenças nas dinâmicas, nos padrões e na difusão das novas tecnologias.

\section{NOTAS}

1. Esse indicador foi desenvolvido para o Relatório de Desenvolvimento Humano 2001 - Making New Technologies Work for Human Development - PNUD.

2. Outro grande desafio para os estatísticos passa além da construção de instrumentos metodológicos relativamente homogêneos capazes de lidar com a disponibilidade de acessos, e alcança a questão dos conteúdos - cujas determinações subjetivas e de difícil quantificação são constituídas no campo da cultura e do conhecimento. Para uma discussão sobre os indicadores nessa área ver Institut de la Statistique du Québec e Unesco Institute for Statistics, 2002.

3. Nesse país, as agências públicas entendem que o problema de estar ou não conectado tem implicações diretas sobre a inserção de determinados indivíduos na sociedade da informação e, ao mesmo tempo, sobre a viabilidade de alguns mercados. Ver Navarro, 2001:31 e segs.
4. Sobre a Pesquisa de Condições de Vida, ver <http:// www.seade.gov.br>.

5. Dentro do escopo da nova versão da pesquisa, haverá uma ampliação dos itens de bens duráveis investigados, com a introdução de uma questão sobre a posse de DVDs. Além disso, haverá uma abordagem em relação ao uso de Internet para os indivíduos escolarizados com mais de sete anos.

6. Os dados para este estudo foram obtidos a partir da aplicação de um questionário complementar à Pesquisa de Emprego e Desemprego, pesquisa domiciliar realizada pela Fundação Seade desde 1985 em convênio com o Dieese. O questionário complementar, especialmente desenvolvido, foi aplicado durante os meses de abril a setembro de 2001. Foram realizadas, aproximadamente, 45 mil entrevistas, com pessoas de 10 anos e mais que sabem ler e escrever. Elas representam 95\% do total de pessoas com 10 anos e mais (População em Idade Ativa - PIA) da RMSP.

7. Entretanto, é necessário ressaltar que, nesse último grupo, os mecanismos de exclusão dentro das empresas estão subordinados às estruturas hierárquicas, que favorecem os quadros de maior remuneração e escolaridade. Segundo dados da pesquisa, entre os indivíduos que dispõem de cargos de planejamento, gerenciamento e direção, $73,8 \%$ têm acesso a computadores e $61,0 \%$ à Internet; entre aqueles que exercem atividades operacionais, essas proporções são de $23,7 \%$ e $13,1 \%$, respectivamente.

8. Considerando apenas a população de estudantes, o acesso à web por meio das escolas alcança cerca de $35 \%$, número, entretanto, bem menor quando se considera a proporção de acessos realizados nos domicílios para o mesmo universo $(73 \%)$.

9. A partir de meados da década de 90, é possível acompanhar o esforço geral dos governos na montagem do governo eletrônico ( $e$ government). Nos EUA, a estimativa do Departamento de Administração e Orçamento do governo federal para o ano 2000 era de que $75 \%$ das transações entre os indivíduos e o governo seriam efetivadas eletronicamente (Neu; Anderson; Bikson, 1999). A importância das novas tecnologias levou a administração Clinton/Gore a promover a Internet como política prioritária para "reinventar o governo". Na Inglaterra, a implementação do governo eletrônico é vista como ponto central para o aumento da governança do Estado, no plano da modernização das políticas públicas. Ver Britain, 1999.

10. Processo a ser reforçado pela necessidade de as prefeituras se enquadrarem nas exigências da Lei de Responsabilidade Fiscal, que requisita a divulgação na Internet de informações sobre execução orçamentária.

11. Em 2001, 95\% das declarações de pessoas físicas foram entregues pela Internet; no caso de pessoas jurídicas esse número chegou a $100 \%$. Ver Ministério do Planejamento, Orçamento e Gestão (2000).

12. No caso do governo do Estado de São Paulo, o esforço para a informatização e modernização do sistema financeiro e orçamentário é objeto de dois programas, ambos financiados pelo BID: o Programa de Modernização da Coordenação da Administração Tributária (Promocat) e o Programa de Modernização do Controle Interno e da Administração Financeira (Promociaf). Além do pregão eletrônico, o governo estadual vem investindo em infra-estrutura para oferecer alguns serviços on-line, como o Poupatempo, pagamento de IPVA, marcação de consultas no Hospital das Clínicas, requisição de editais, verificação de multas e cadastro de veículos, Boletim de Ocorrência, acesso a informações socioeconômicas e demográficas do Estado, o Acessa São Paulo, entre outros. Ver Prandi; Mori, 2000.

13. Esse produto é uma iniciativa da Secretaria de Governo e Gestão Estratégica e tem como executores a Fundação Sistema Estadual de Análise de Dados - Seade e a Companhia de Processamento de Dados do Estado de São Paulo - Prodesp, 2001.

14. Castells (1999) definiu as tecnologias de informação como um conjunto convergente dessas tecnologias. 
15. O termo "atividade" é mais usado quando se refere a e-business.

16. <http://e-com.ic.gc.ca/english/links/814.html>.

17. <http://www.eito.com>.

18. <http://www.wto.org/>.

19. Entendida como natureza dos modelos de negócios das redes que suprem as transações.

20. Como o Programa Acessa São Paulo que o Governo do Estado de São Paulo desenvolve. Ver <http://www.acessasaopaulo.sp.gov.br/>.

21. O segmento final de um endereço eletrônico que identifica a rede local, a instituição ou o provedor de acesso.

\section{REFERÊNCIAS BIBLIOGRÁFICAS}

BESSA, V. de C.; TÁPIA, J.R.B. Exclusão digital e cidades mundiais: a experiência de São Paulo. In: SILVEIRA, S.A.; CASSINO, J. (Orgs.). Software livre e inclusão digital. São Paulo: Conrad Editora do Brasil, 2003, p.77-100.

BRITAIN, Cabinet Office. Modernising government, March, 1999.

CASTELlS, M. A sociedade em rede. São Paulo: Paz e Terra, 1999.

COHEN, S.S. et al. Tools for throught: what is new and important about the "e-economy", Berkeley Roundtable on the International Economy, University of California at Berkeley, 2000.

COLECCHIA, A. Reviewing the ICT sector definition: issues for discussion. $16^{\text {th }}$ MEETING OF THE VOORBUR GROUP ON SERVICES STATISTICS, Örebro, Sweden, 17-21 september 2001.

COLECCHIA, A. et al. Defining and measuring eletronic commerce. Paris, OECD, February 2000 (Discussion paper).

CURRÁS, M.B.; NANCLARES, N.H.; LÓPEZ, F.L. The debate surrounding the new economy: an approach for an analysis, 2001. Disponível em: <http://ideas.repec.org/p/nav/ecupna/0110.html $>$. Acesso em: 24 set. 2003.

DEPARTAMENTO DE COMÉRCIO DOS ESTADOS UNIDOS. Falling through the Net: defining the digital divide, Washington, DC: Administração Nacional de Informação e Telecomunicações, 2000 .

Falling through the Net: defining the digital divide, Washington, DC, Administração Nacional de Informação e Telecomunicações, 1999.

Falling through the Net: a survey of the net: new data on the digital divide. Washington, DC, Administração Nacional de Informação e Telecomunicações, 1997.

Falling through the Net: a survey of the have-nots in rural and urban America. Washington, DC, Administração Nacional de Informação e Telecomunicações, 1995.

FAPESP. Indicadores de ciência e tecnologia e inovação em São Paulo - 2001. São Paulo: Fapesp, 2002.

FUNDAÇÃO SEADE. São Paulo em Perspectiva, São Paulo, v.13, n.1-2, jan./jun. 1999

GEBAUER, J.; BEAM, C.; SEGEV, A. Impact of the Internet on procurement. Paper submitted to Acquisition Review Quarterly, 1998.

INSTITUT DE LA STATISTIQUE DU QUÉBEC; UNESCO Institute for Statistics. INTERNATIONAL SYMPOSIUM ON CULTURE STATISTICS. Proceedings ... Montréal, 21 to 23 october, 2002.

KONDO, E.K. Desenvolvendo indicadores estratégicos em ciência e tecnologia: as principais questões. Ci. Inf., Brasília, v. 27, n. 2, p. 128-133, maio/ago. 1998.
MANSELL, R.; WEHN, U. Knowledge societies: information technology for sustainable development. Oxford: University Press, 1998 .

MESENBOURG, T.L. Measuring the Digital Economy, U.S. Bureau of the Census, 2001.

MINISTÉRIO DO PLANEJAMENTO, ORÇAMENTO E GESTÃO Proposta de politica de governo eletrônico para o poder executivo federal. Brasília, DF: 2000. Disponível em: $<$ http:// www.governoeletronico.gov.br>. Acesso em: 20 set. 2000

NAVARRO, T.R. Exclusão digital ou infoinclusão? A experiência norte-americana nos anos 90. Campinas, CNPq/Unicamp, Instituto de Economia, 2001 (Relatório de iniciação científica).

NERI, M.C. Mapa da exclusão digital. Rio de Janeiro: FGV/Ibre, CPS, 2003. $143 \mathrm{p}$.

NEU, R.C.; ANDERSON, R.H.; BIKSON, T.K. Sending you government a message: e-mail communication between citizens and government, 1999 Disponível em:

$<$ http://www.Radn.org/publication/MR/MR/1095/>. Acesso em 24 set. 2003

OECD. Committee for information, computer and comunication policy: measuring eletronic commerce. Paris, OECD/GD, v.97, n.185, 1997.

The measurement of scientific and technical activities: proposed guidelines for collecting and interpreting technological innovation data - Oslo Manual. Paris, 1996.

The measurement of scientific and technical activities: human resources in science \& technology - Canberra Manual. Paris, OECD/GD, v.95, n.77, 1995 .

. The measurement of scientific and technical activities standard practice for surveys of research and experimental development - Frascati Manual. Paris, 1993.

PNUD. Relatório do Desenvolvimento Humano 2002: aprofundar a democracia num mundo fragmentado. Programa das Nações Unidas para o Desenvolvimento, 2002.

PRANDI, M.L.; MORI, P. Crise e reforma do Estado no Brasil. $\mathrm{Ca}$ dernos do Fórum Século XXI. São Paulo, Diário Oficial do Estado de São Paulo, Assembléia Legislativa de São Paulo/Fundação Seade, 2000.

PORCARO, R.M. A mensuração da economia eletrônica no sistema de informação estatística, IBGE/DPE/Demet, texto base do Seminário realizado em 12 de dezembro de 2001.

SAGASTI, F.; JOHANSSON, C.; FUKUDA-PARR, S.; DESAI, M. Measuring technology achievement of nations and the capacity to participate in the network age. PNUD, 2001. Disponível em: $<$ http://www.statistics.gov.uk/IAOSlondon $2002 /$ contributed_papers/IP_Desai.as>. Acesso em: 24 set. 2003.

SCHREYER, P. The contribution of information and communication to output growth: a study of the G7 countries. DOC 2, OECD, Directorate for Science, Technology and Industry, DSTI/mar. 2000

SEDISI. Asociación Española de Empresas de las Tecnologías de la Información, Metrica de la Sociedad de la Información Datos 1999-2000, noviembre de 2001. Disponível em: $<$ http://www.campus-oei.org/salacts:/>. Acesso em: set.2003.

SILVEIRA, S.A. O novo desafio da democracia na sociedade da informação. Anuário de Jornalismo da Cásper Líbero. São Paulo: Fundação Cásper Líbero, 2000.

STATISTICS CANADA. A reality check to defining e-commerce, CGI Information Systems and Management Consultants Inc., Canada, 1999 
TAKAHASHI, T. Sociedade da informação no Brasil: livro verde. Brasília, Ministério da Ciência e Tecnologia, 2000.

TÁPIA, J.R.B. (Org.). A difusão das tecnologias da informação na economia paulista nos anos 90. Campinas: Instituto de Economia da Unicamp, 2000. Mimeografado.

TÁPIA, J.R.B.; RALLET, A. Telecomunicações, desregulamentação e convergência tecnológica. Uma análise comparada. Campinas, Ed. da Unicamp, 2000.

TIGRE, P.B. Agenda de Pesquisas e Indicadores para Estudos de Difusão de Tecnologias da Informação e Comunicação. Brasília, Ipea, nov. 2002. (Texto para discussão n.920).

U.S. DEPARTAMENT OF COMMERCE. The emerging digital economy II. Washington: Economic and Statistics Administration/ Office of Policy Development, 1999.

UNESCO. Division of Science Policy and Analysis. Science \& technology statistics and indicators in developing countries: perspectives and challenges. Working Paper. Montreal: 2002. Disponível em: <http://www.unesco.org/pao/events/it.htm>. Acesso em: 10 ago. 2003.
UNITED NATIONS. E-Commerce and Development Report, UNCTAD/SDTE/ECB/2, Executive Summary, New York and Geneva, 2002.

WONG, J.; LAM, E. Measuring electronic commerce in Singapore: methodological issues and survey findings. Singapore Department of Statistics, 1999.

ZABELSKY, T.E. Measuring the information sector in census bureau program. $12^{\text {th }}$ MEETING OF THE VOORBUR GROUP ON SERVICES STATISTICS, Copenhagem, 15-19 september, 1997.

Vagner de Carvalho Bessa: Geógrafo, Analista da Fundação Seade (vagner@seade.gov.br).

Marcelo Batista Nery: Sociólogo, Analista da Fundação Seade (mbnery@ltid.inpe.br).

Daniela Cristina Terci: Economista, Analista da Fundação Seade (daniela@seade.gov.br). 